\title{
Comparison of conjugation procedures for the preparation of monoclonal antibody-enzyme conjugates
}

\author{
Antoinette Jeanson, Jean-Michel Cloes, Mireille Bouchet and Bernard Rentier \\ Fundamental Virology and Immunology Unit, Microbiology Department, Pathology B23, University of Liège, \\ Liège, Belgium
}

\begin{abstract}
Four monoclonal antibodies belonging to different subclasses and with differing isoelectric points were coupled to horseradish peroxidase (HRP) and alkaline phosphatase (AP) using various conjugation procedures. The conjugates were tested by enzyme immunoassay and their efficiency was characterized by the antibody and enzyme concentrations needed to obtain an arbitrary OD value. The suitability of antibody for conjugation through $\mathrm{NH}_{2}$ groups was tested by fluorodinitrobenzene (FDNB). HRP conjugates were produced by two variants of the sodium periodate procedure and two variants of the glutaraldehyde method, as well as by the heterobifunctional linker N-succinimidyl 3-(2-pyridyldithio)pro-pionate (SPDP). Two of the four antibodies were coupled by a third variant of the periodate method, through their carbohydrate moieties. The periodatemediated conjugations, using sugar moieties on the enzyme, provided the most efficient HRP conjugates, regardless of the antibody subclass or isoelectric point. The glutaraldehyde procedures consistently gave the worst results. AP conjugates were prepared using the same methods. The most efficient and reproducible AP conjugates with all four monoclonal antibodies were obtained using the SPDP procedure. The efficiency of the other methods differed from one antibody to another.
\end{abstract}

Key words: Immunochemical method; Conjugation procedure; Monoclonal antibody; Peroxidase; Phosphatase; Enzyme immunoassay

\begin{abstract}
Abbreviations: SPDP, N-succinimidyl 3-(2-pyridyldithio) propionate; HRP, horseradish peroxidase; AP, alkaline phosphatase; ABTS, 2,2'-azino-di-(3-ethylbenzthiazoline sulfonate); PNP, $p$-nitrophenyl phosphate; EIA, enzyme immunoassay; IgG, immunoglobulin G; PBS, phosphate-buffered saline; RAM, rabbit Ig antimouse Ig; ConA, concanavalin A; FDNB, fluorodinitrobenzene; OD, optical density.
\end{abstract}

\section{Introduction}

Many procedures have been described for enzyme-antibody conjugation, and their efficiencies differ widely (O'Sullivan and Marks, 1981). Most of them couple enzymes to amino groups of Igs, some use reagents such as sodium periodate or glutaraldehyde, which lead to variable size combinations while others, using bifunctional linkers such as SPDP, generate homogenous populations of heteroconjugates (Nilsson et al., 1981). Recently, O'Shannessy and Quarles (1985) have described the loss of antigen-binding activity associated with aminodirected labeling. In order to overcome this problem they proposed a method which they considered to be universally efficient, based on coupling the enzyme to the carbohydrate moieties of Igs (the latter are not involved in the antigen binding site (Ghose et al., 1983)).

Burkot et al. (1985) suggested that FDNB be used to screen monoclonals and to predict those which would be altered by amino-directed labeling.

When synthesizing a conjugate, one is interested in obtaining a product which, besides its high activity, is also cost efficient. In other words, among different conjugates, one will choose the one that gives a pre-determined OD value in EIA at the lowest initial antibody and enzyme concentrations. Such information is strikingly absent in the specialized literature.

We have compared the most popular conjugation procedures of antibodies to the enzymes horseradish peroxidase (HRP) and alkaline phosphatase (AP), using a panel of monoclonal antibodies of well defined specificities and different isotypes. In this report we describe the choice of an optimal conjugation procedure, in terms of cost and of enzymatic and antigen-binding activities. 


\section{Materials and methods}

Monoclonal antibodies

\begin{tabular}{llll}
\hline Name & Specificity & Isotype & Isoelectric point \\
\hline 43.6 C9 & Human IgG & IgGl & 6 \\
L5.F2.C3 & Human IgA & IgG2b & 8.5 \\
74.8.B10 & Human IgA & IgGl & 7 \\
3F9.B8.E3 & $\begin{array}{l}\text { Human IgG3 (MET) (anti- } \\
\text { idiotype) }\end{array}$ & & 7 \\
\hline
\end{tabular}

The monoclonal antibodies were produced by fusion of the mouse myeloma cell line SP 2/0-ag 14 (Shulman et al., 1978) and spleen cells from immunized BALB/c mice. They were produced in the ascitic fluids of syngeneic mice.

\section{Enzymes, immunological and chemical reagents}

HRP (batch no. 10814623-08) and AP (batch no. 10695624-59), both EIA grade, were purchased from Boehringer, Mannheim, F.R.G., as well as the HRP substrate ABTS. PNP tablets were from Sigma, St. Louis, MO. Protein A-Sepharose CL-4B, ConA-Sepharose and SPDP were from Pharmacia Fine Chemicals, Sweden. Glutaraldehyde (EM grade) was from Taab Laboratories, U.K. $\mathrm{NaIO}_{4}$ and FDNB were from UCB, Belgium.

Human antigens IgG, IgA and IgG3(MET) were a gift from the Blood Transfusion Center, Liège, Belgium, RAM-HRP and RAM-AP were purchased from Dako, Denmark.

\section{Antibody purification}

Monoclonal antibodies were purified from ascitic fluids by affinity chromatography on Protein A-Sepharose, according to Ey et al. (1978). Purity was verified by immunoelectrophoresis (IEP).

\section{FDNB treatment}

Ascitic fluids were treated by FDNB according to Burkot et al. (1985).

\section{Conjugation procedures}

HRP was conjugated to antibodies by the following methods:

(1) one-step glutaraldehyde (Boorsma and Kalsbeek, 1975);

(2) periodate, using sugar moieties of the enzyme, according to Tijssen and Kurstak (1984);

(3) periodate, using sugar moieties of the enzyme, according to Nakane et al. (1974), except for IgG2b L5.F2.C3;

(4) periodate, using sugar moieties of the IgG (O'Shannessy and Quarles, 1985), tested only on IgGl 43.6.C9 and IgG2b L5.F2.C3;

(5) SPDP (Carlsson et al., 1978).

AP was conjugated to antibodies by the following methods:

(1) one-step glutaraldehyde (Engvall and Perl-mann, 1971);

(2) two-step glutaraldehyde as recommended by Boehringer, Mannheim, F.R.G.;

(3) periodate, using sugar moieties of the enzyme (Williams, 1984), with AP/Ig ratios of 1 and 4;

(4) periodate, using sugar moieties of the IgG (O'Shannessy and Quarles, 1985), tested only with IgGl 43.6.C9. Synthesis of AP-hydrazide was performed according to Keren et al. (1986). A protein ratio of 1 was used;

(5) SPDP (Carlsson et al., 1978) adapted for AP: SPDP/AP ratio of 60, SPDP/Ig ratio of 3, AP/Ig ratio of 1; AP was the molecule treated with dithiothreitol.

\section{Affinity chromatography}

Unreacted IgG was removed using a slightly modified version of the method described by Lanner et al. (1978). Half the amount of each HRP conjugate (4-8 mg protein) was run on a freshly packed $0.9 \times 10 \mathrm{~cm}$ ConA- 
Sepharose column equilibrated in PBS. The adsorbed material was eluted by the addition of $0.5 \mathrm{M} \alpha$-methyl-Dmannoside to the buffer. Each fraction was tested in EIA in order to detect the presence of active conjugates and of antibodies with antigen binding activity. Fractions containing antigen binding activity only were discarded. The pool of the others and the other half of non-purified conjugate, adjusted to the same volumes, were compared by EIA. The same resin was used, before conjugation, to detect any impurities in the IgG preparations that would bind to the lectin.

EIA

EIAs were carried out in microtiter plates (Nunc, 4-39454-96F) using a technique derived from Voller et al. (1976). In order to compare the activities of the conjugates, plates were coated overnight at $4{ }^{\circ} \mathrm{C}$ with $50 \mathrm{ng} / \mathrm{well}$ of antigens diluted in $0.05 \mathrm{M}$ sodium carbonate-bicarbonate buffer ( $\mathrm{pH} 9.6$ ) containing $0.02 \%$ (w/v) $\mathrm{NaN}_{3}$. Wells were washed twice with deionized water and then saturated for $45 \mathrm{~min}$ with a $0.02 \mathrm{M}$ phosphate buffer containing $0.15 \mathrm{M} \mathrm{NaCl}, 2 \%(\mathrm{w} / \mathrm{v})$ ovalbumin and $0.05 \%$ (v/v) Tween 20 at $20{ }^{\circ} \mathrm{C}$. Serial dilutions of conjugates were then added in $0.05 \mathrm{ml}$ volumes and incubated for $1 \mathrm{~h}$ at $37^{\circ} \mathrm{C}$. After five more washings with deionized water, the substrates ABTS $\left(0.75 \mathrm{mg} / \mathrm{ml}\right.$ in citrate buffer, $\mathrm{pH} 5.6$, added with $0.0012 \% \mathrm{H}_{2} \mathrm{O}_{2}$ extemporaneously) for HRP conjugates, and PNP (one $5 \mathrm{mg}$ tablet $/ 5 \mathrm{ml}$ ) diluted in diethanolamine buffer, $\mathrm{pH} 9.8$ for AP conjugates, were added in $0.05 \mathrm{ml}$ volumes to the wells. After a $30 \mathrm{~min}$ incubation at $37^{\circ} \mathrm{C}, 0.15 \mathrm{ml}$ deionized water (for HRP conjugates) or $\mathrm{NaOH} 0.4 \mathrm{~N}$ (for AP conjugates) was added. Absorbances were measured at $414 \mathrm{~nm}$ (HRP conjugates) or $405 \mathrm{~nm}$ (AP conjugates) in a Titertek Multiskan photometer (Flow Laboratories, France).

Since the enzymes were from homogeneous batches, with the same specific activity, the conjugation yields were determined in terms of the concentrations necessary to obtain a predetermined immunoenzymatic activity in EIA. In this way, relative yields could be compared.

In order to compare the antigen binding activities of the conjugates, indirect tests were performed as follows:

(1) antigen coating;

(2) serial dilutions of conjugates;

(3) RAM-AP (HRP conjugates) or RAM-HRP (AP conjugates);

(4) substrates.

The same type of test was used to compare the ascitic fluids before and after treatment by FDNB.

\section{Measurement of enzymatic activities}

Activities of conjugated and unconjugated enzymes were measured in microtiter plates: serial dilutions and substrates were added in $0.05 \mathrm{ml}$ volumes. After $2 \mathrm{~min}$ at $37^{\circ} \mathrm{C}, 0.1 \mathrm{ml}$ deionized water (HRP) or $\mathrm{NaOH} 0.4 \mathrm{~N}$ (AP) was added and absorbances measured as described above.

\section{Results}

\section{Effect of FDNB treatment}

Antigen binding activities of the monoclonal antibodies IgG1 74.8.B10 and IgG2b L5.F2.C3 were not affected by FDNB. However, the activity of IgGl 43.6.C9 decreased about five times and that of IgG2a 3F9.B8.E3 was completely inhibited (Table I). Their antigenicity was slightly decreased, but to a lesser extent than the antigen binding activity. In spite of these results, we attempted to conjugate the two latter monoclonals through their amino groups and compared the products with the same antibodies, coupled through the carbohydrate moiety of the Ig.

\section{TABLE I}

ANTIGEN BINDING ACTIVITY (INDIRECT EIA) AND ANTIGENICITY (DIRECT EIA) EXPRESSED AS THE SAMPLE DILUTION GIVING AN OD $(414 \mathrm{NM})=$ 0.8, OF IGGL 43.6.C9 AND IGG2A 3F9.B8.E3 WITH OR WITHOUT TREATMENT BY FDNB

\begin{tabular}{llllc}
\hline & \multicolumn{2}{l}{ IgGl 43.6.C9 } & & \multicolumn{2}{l}{ IgG2a 3F9.B8.E3 } \\
\cline { 2 - 5 } & $\begin{array}{l}\text { No FDNB } \\
\text { treatment }\end{array}$ & $\begin{array}{l}\text { FDNB } \\
\text { treatment }\end{array}$ & $\begin{array}{l}\text { No FDNB } \\
\text { treatment }\end{array}$ & $\begin{array}{c}\text { FDNB } \\
\text { treatment }\end{array}$ \\
\hline Antigen binding & & & & \\
activity & 4625 & 920 & 7350 & 0 \\
Antigenicity & 2125 & 1280 & 4060 & 1850 \\
\hline
\end{tabular}


Efficiency of IgGl 43.6.C9-HRP and IgG2b L5.F2.C3-HRP conjugates using the carbohydrate coupling of O'Shannessy and Quarks (1985)

IgGl 43.6.C9 was coupled to HRP-hydrazide after preliminary treatment of the $\mathrm{Ig}$ by $\mathrm{NaIO}_{4} 0.1 \mathrm{M}$ at $20{ }^{\circ} \mathrm{C}$ and at $0^{\circ} \mathrm{C}$. It was also labeled with AP-hydrazide after treatment by $\mathrm{NaIO}_{4}$ at $20^{\circ} \mathrm{C}$. No satisfactory result was obtained with this monoclonal at either temperature with either enzyme (data not shown). In order to determine whether conjugate inactivity was due to enzyme treatment or to IgG treatment, we compared the activity of HRP-hydrazide to that of HRP (Table II) and the antigen binding activity and antigenicity of one of the HRP conjugates (IgG treated with $\mathrm{NaIO}_{4} 10 \mathrm{mM}$ at $20^{\circ} \mathrm{C}$ ) to untreated $\mathrm{IgGl}$ 43.6.C9 (Table III).

IgG2b L5.F2.C3 was coupled to HRP-hydrazide after treatment by $\mathrm{NaIO}_{4} 10 \mathrm{mM}$ and $2.5 \mathrm{mM}$, at $0^{\circ} \mathrm{C}$ : The conjugate treated by $\mathrm{NaIO}_{4} 10 \mathrm{mM}$ was active in direct EIA, but with a low efficiency compared to that of the conjugate synthesized by Tijssen's method (data not shown).

\section{Affinity of the IgG preparations for ConA}

Fig. 1 shows the elution diagram from a ConA-Sepharose column of protein A-purified subclass IgG1 43.6.C9 monoclonal antibody. Antigen binding activity of the $\mathrm{IgG}$ was almost entirely recovered in the second peak eluted without buffer change. A small amount of antigen binding activity was found in the mannoside-eluted peak but it was discarded. Other IgGs yielded almost identical separation patterns as in Fig. 1.

Fig. 1. Affinity chromatography of the mouse IgGl monoclonal 43.6.C9 on ConA-Sepharose column. The arrow indicates the addition of $0.5 \mathrm{M} \alpha$-methyl-D-mannoside.

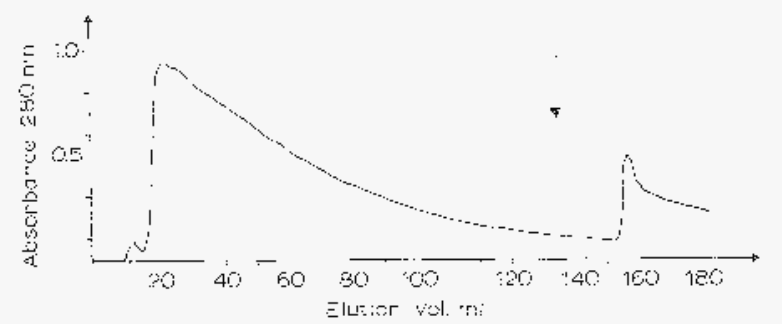

\section{TABLE II}

ENZYMATIC ACTIVITIES OF HRP AND HRP-HY-DRAZIDE, EXPRESSED IN $\mu g$ ENZYME/ml GIVING AN OD (414 nm) OF 0.8

\begin{tabular}{ll}
\hline HRP & HRP-hydrazide \\
\hline 0.63 & 0.56 \\
\hline
\end{tabular}

\section{TABLE III}

ANTIGEN BINDING ACTIVITY, EXPRESSED AS THE CONCENTRATION OF IgG (ng/ml) GIVING AN OD (405 nm) OF 0.8, AND ANTIGENICITY, EXPRESSED AS THE CONCENTRATION OF IgG (ng/ml) GIVING AN OD (405 nm) OF 1.0, OF IgGl 43.6.C9 BEFORE AND AFTER CONJUGATION TO HRP-HYDRAZIDE

\begin{tabular}{|c|c|c|}
\hline & Unconjugated IgG & Conjugated IgG \\
\hline Antigen binding activity & 10 & 365 \\
\hline Antigenicity & 940 & 635 \\
\hline
\end{tabular}

\section{HRP conjugates}

Chromatography. The elution diagrams (not shown) of the four conjugates (glutaraldehyde, Nakane's periodate, Tijssen's periodate and SPDP) suggest that the proportion of unreacted IgG is very small in the glutaraldehyde conjugate, as shown by Nilsson et al. (1981), and larger in the three others. In the case of periodate conjugates, part of the colored material (thus containing HRP) displaying an affinity for the lectin could be eluted neither with $0.5 \mathrm{M} \alpha$-methyl-D-mannoside, nor with the washing buffers $0.5 \mathrm{M} \mathrm{NaCl} \mathrm{pH} 4.5$ or 8.5. Fig. 2 compares mannoside eluted peaks with the corresponding non-purified samples. The purification yield was unsatisfactory in all cases: the activity of purified conjugates was lower than that of the non-purified conjugates. The activities of SPDP conjugates were similar at higher dilutions, but at low dilutions the purified conjugates were more 
active. Since affinity purification did not increase the yield of three conjugates, we used crude conjugates for subsequent experiments.

Fig. 2. Conjugate (IgGl 43.6.C9-HRP) activity tested by EIA before (continuous line) and after (dotted line) affinity chromatography. $\triangle, S P D P(a) ; O$, periodate (Nakane) $(b) ; \bullet$, periodate (Tijssen) (c); glutaraldehyde $(d)$.
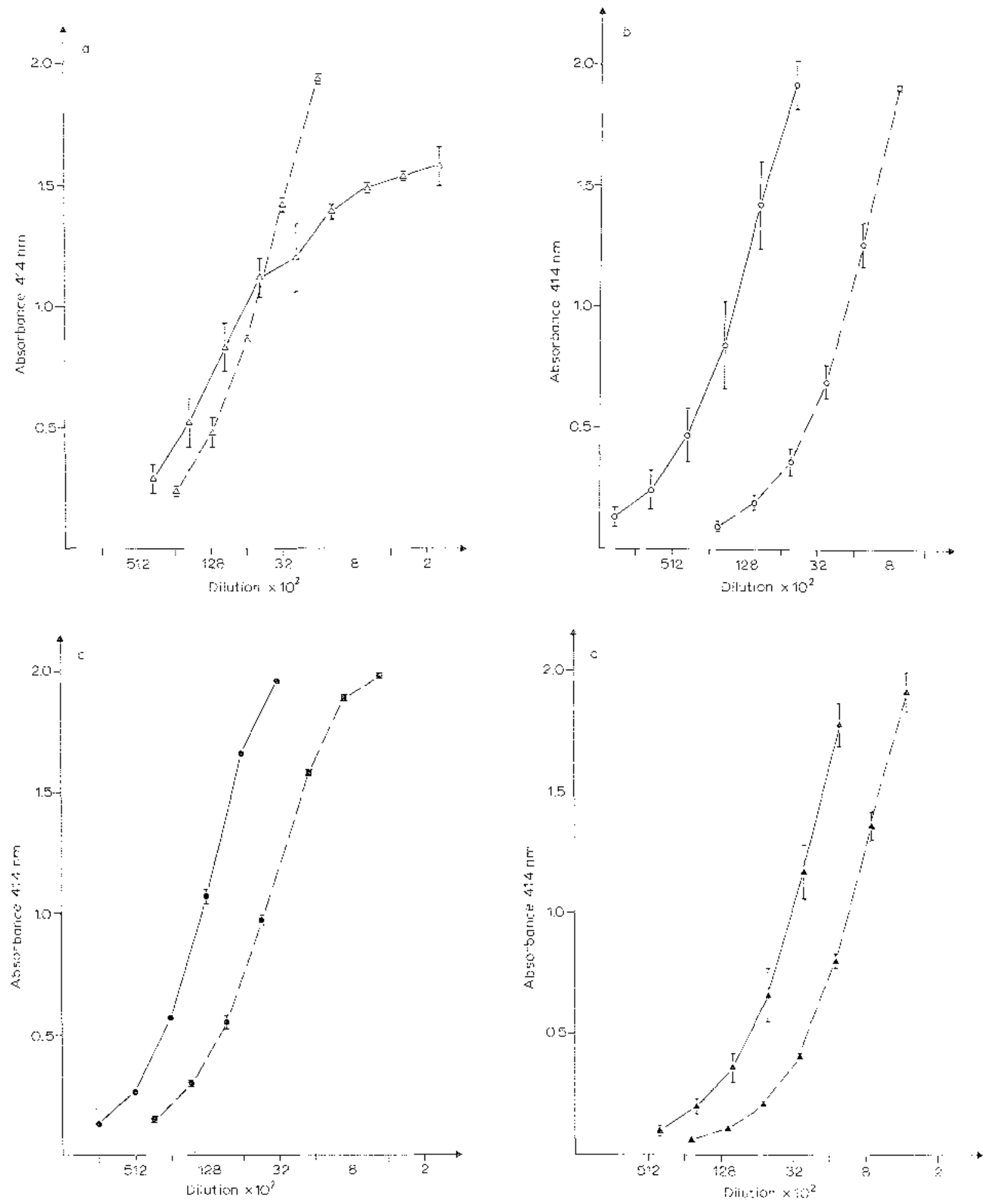
Antigen binding activity. The effect of conjugation on antigen binding activity was tested with two antibodies. Fig. 3 shows EIA curves obtained with conjugate IgGl 43.6.C9-HRP. Conjugate IgGl 74.8.B10 gave identical results. SPDP conjugation proved the least damaging whereas the glutaraldehyde procedure seemed to decrease the activity dramatically. Periodate coupling yielded intermediate results.

Fig. 3. Antigen binding activity of IgGl 43.6.C9-HRP conjugates tested by indirect EIA. $\triangle$, SPDP; O, periodate (Nakane); (b) •, periodate (Tijssen); , glutaraldehyde; , IgG before conjugation.

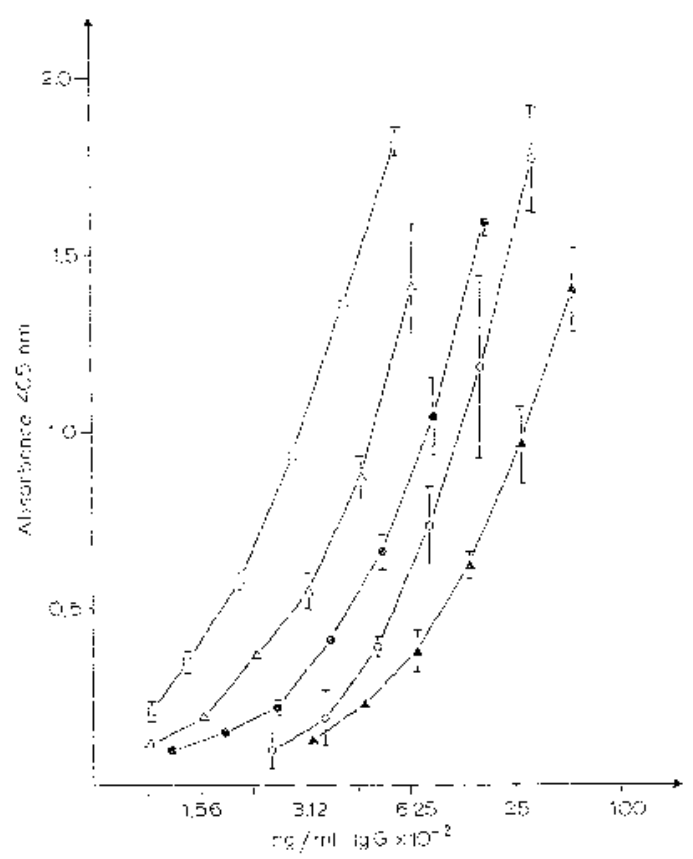

Enzyme activity. The effect of conjugation on HRP activity was investigated with conjugates IgGl 43.6.C9-HRP, IgG1 74.8.B10 and IgG2a 3F9.B8.E3. Fig. 4 shows that enzymatic activity was maintained in all conjugates and was highest with glutaraldehyde coupling.

Fig. 4. HRP activity of IgGl 74.8.B10 conjugates, ,SPDP; O, periodate (Nakane); O, periodate (Tijssen); , glutaraldehyde; , HRP before conjugation.

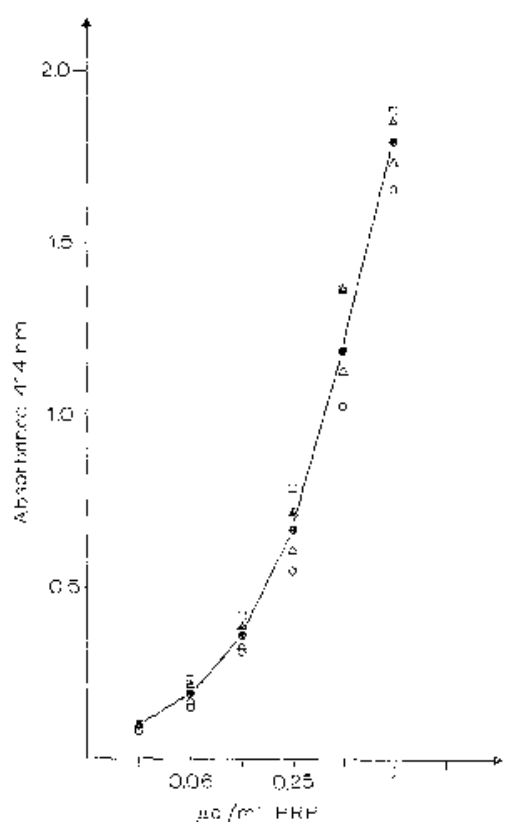


Global conjugate activity. Conjugate activity in EIA was expressed in terms of the initial IgG and enzyme concentrations (since HRP used in all of the experiments was from the same batch) necessary to reach a predeterminated OD value. Fig. 5 shows the curves obtained for each of the four antibodies tested. In all cases, periodate conjugates consumed less HRP and IgG than SPDP and glutaraldehyde conjugates when expressing similar levels of activity.

Fig. 5. Activity of IgGl 43.6.C9 (a), IgGl 74.8.B10 (6), IgG2a 3F9.B8.E3 (c) and IgG2b L5.F2.C3 (d) HRP conjugates, ,SPDP; O, periodate (Nakane); •, periodate (Tijssen); , glutaraldehyde.
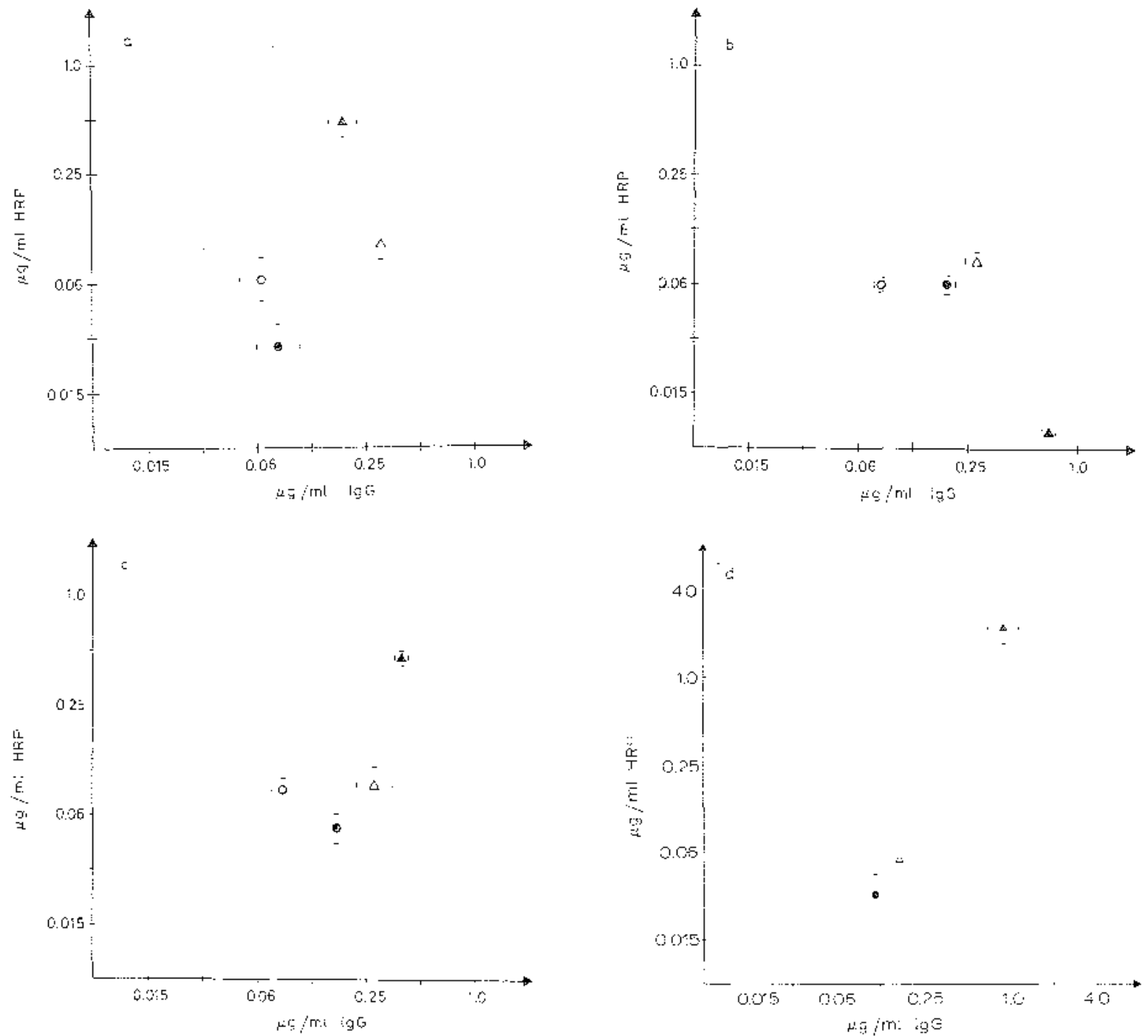

\section{AP conjugates}

The investigations performed with HRP conjugates were also performed with AP conjugates. However, the SPDP procedure had not been previously described and the optimal conditions for this coupling (i.e., SPDP/AP and $\mathrm{AP} / \mathrm{IgG}$ ratios which provided the most efficient conjugates) had to be determined. The best results were obtained using $60 \mathrm{~mol}$ SPDP per mol AP, 3 mol SPDP per mol IgG and equimolar amounts of AP and IgG (data not shown).

Antigen binding, enzymatic and global conjugate activities. As for HRP conjugates, no correlation was found between antigen binding and conjugate activity. Glutaraldehyde conjugates were best able to retain enzymatic activity. The enzymatic activity of SPDP and periodate conjugates was slightly decreased, but not enough to account for the differences between global conjugate activities (Figs. 6 and $l b$ ). The SPDP procedure may not be superior in every instance but in the present study it performed consistently well. When periodate was used, the 4:1 ratio yielded better conjugates than the 1:1 ratio (except in the case of IgG2b L5.F2.C3). The conjugate 
prepared by coupling IgGl 43.6.C9 via its carbohydrate groups by the method of O'Shannessy and Quarles (1985) was inactive.

Fig. 6. Antigen binding activity (a) and AP activity (b) of IgGl 74.8.B10-AP conjugates. $\triangle$, SPDP; $O$, periodate $1: 1 ; \bullet 4: 1 ; \quad$, one-step glutaraldehyde; . two-step glutaraldehyde; $\oslash, \operatorname{Ig} G(a)$ or $A P(b)$.
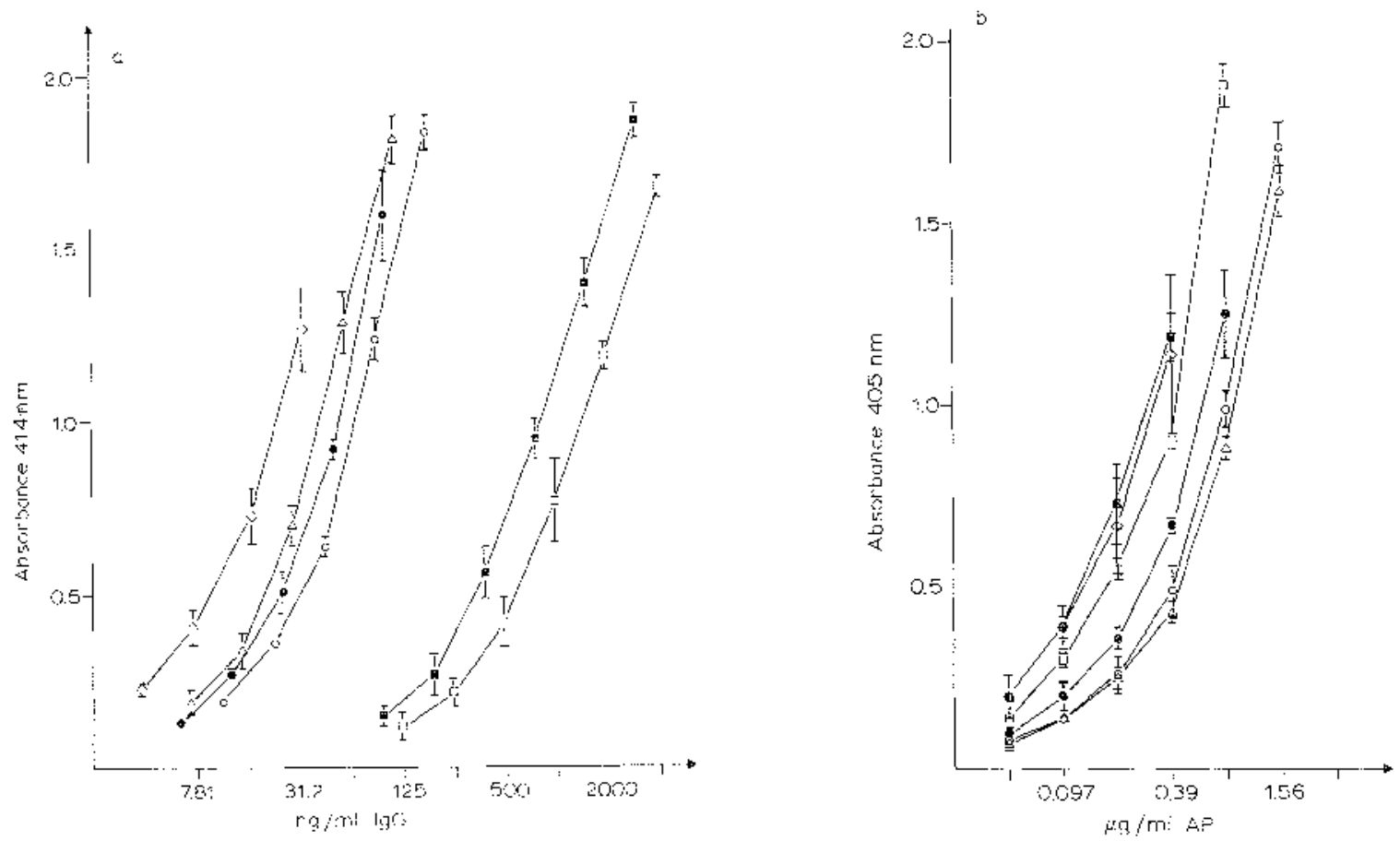

\section{Discussion}

In contrast to the observations of Burkot et al. (1985), we were unable to find a clear correlation between sensitivity to FDNB, and the suitability of antibodies for conjugation through primary amino groups. Indeed, in our hands, this type of conjugation, for HRP or AP, was equally efficient whether the antibodies were sensitive or insensitive to FDNB. We verified that the antigenicity of FDNB sensitive antibodies was not or only slightly affected by FDNB treatment. This supports Burkot's claim that FDNB derivatives do not interfere with the binding of conjugates to antigens in the indirect EIA. Moreover, SPDP and aldehydes do not seem to react with amino groups in the antigen binding site of the antibodies and alternative labeling of other moieties was thus not necessary. However, to render this study more generally useful, we included a comparison of the amino labeling techniques with the conjugation method using oligosaccharide moieties as proposed as universal by O'Shannessy and Quarles (1985).

Coupling of IgGl 43.6.C9 (FDNB sensitive) to HRP-hydrazide and AP-hydrazide yielded inactive or only slightly active conjugates, regardless of the temperature during $\mathrm{NaIO}_{4}$ treatment. We verified that the enzymatic activity of HRP treated with adipic hydrazide was similar to the activity of non-treated HRP. However, the antigen binding activity of IgGl 43.6.C9 was reduced compared to that of untreated IgGl, while antigenicity was only slightly decreased. Coupling of IgG2b L5.F2.C3 (FDNB insensitive) to HRP-hydrazide yielded an active conjugate, but with a low activity compared to that of the best amino conjugates. O'Shannessy and Quarles (1985) discussed the importance of variations in the oligosaccharidic structure of monoclonal antibodies. The $\mathrm{NaIO}_{4}$ treatment conditions used may have been too severe for some antibodies, resulting in the destruction of the sugar moieties. Hence, we suggest that this method may not be as generally useful as expected.

In order to evaluate the efficacy of the amino conjugations, the yields of enzymatic, antigen binding and global conjugate activity were measured. Both HRP and AP activities were relatively well maintained during all procedures, mainly in the glutaraldehyde conjugates, probably since glutaraldehyde conjugation does not imply subsequent treatment unlike other techniques.

Two factors appear to influence antigen binding activity: the conjugation procedure itself and steric hindrance on IgG molecules. After glutaraldehyde conjugation, the formation of large and irregular IgG-HRP complexes leading to steric hindrance is likely to be the most important factor. 
As far as global conjugate activity was concerned, Nakane's technique (tested on three antibodies) provided slightly more efficient conjugates in terms of initial IgG input, while Tijssen's conditions proved superior in terms of initial HRP input. This could be explained by the different HRP: IgG ratios used for each variant of the periodate method: 3.75 (Nakane) and 1.25 (Tijssen), thus the fact that the proportion of unconjugated HRP (which does not interfere with direct EIA) is probably higher in conjugates obtained by Nakane's technique. The latter also proved to be more reproducible than Tijssen's method.

The antigen binding activity of SPDP conjugates was higher than that of both periodate conjugates whereas its global conjugate activity was lower. This suggests that the SPDP procedure could still be optimized further, by varying the SPDP: IgG, SPDP: HRP and HRP : IgG ratios, for instance. It is also noteworthy that the SPDP technique is applicable to all murine IgGs, regardless of their subclass or isoelectric point. Moreover, SPDP conjugation is efficient and much more reproducible than the alternative techniques used to prepare AP conjugates.

In conclusion, periodate conjugation techniques using the amino groups of IgGs and the oligosaccharide moieties of HRP were the most satisfactory for all four monoclonal antibodies tested, regardless of their isotype, isoelectric point and reactivity to FDNB. Our adaptation of the SPDP method was superior for AP conjugates, under all of the experimental conditions tested.

Fig. 7. Activity of IgGl 43.6.C9 (a), IgGl 74.8.B10 (b), IgG2a 3F9.B8.E3 (c) and IgG2b L5.F2.C3 (d) AP

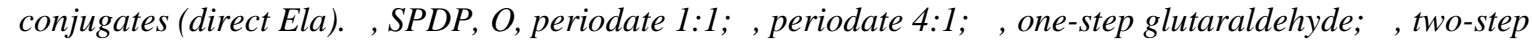
glutaraldehyde.
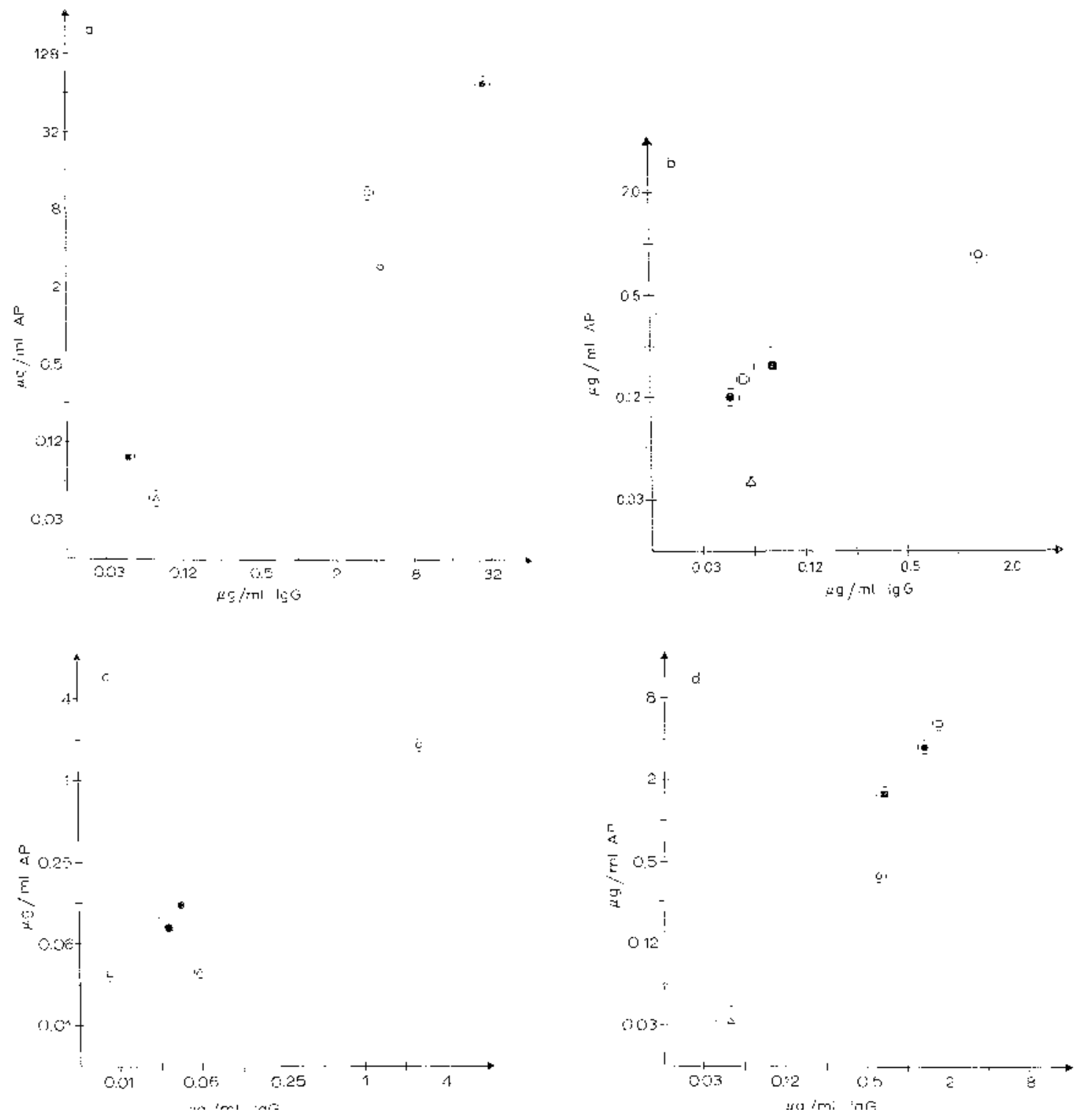


\section{Acknowledgements}

The authors wish to thank C. Meunier for skilful technical assistance, Dr. D. Sondag-Thull for providing antigens, Dr. P. Hainaut for helpful discussions and Dr. F. Cremer for isoelectrofocus-ing determinations. This work was performed under the contract PREST/ULg/12 and contract no. 83-88/48 of 'Actions Concertées' with the Belgian Prime Ministry Services (Programmation de la Politique Scientifique). The authors take full scientific responsibility for this text.

\section{References}

Boorsma, D.M. and Kalsbeek, G.L. (1975) A comparative study of horseradish peroxidase conjugates prepared with a one-step and a twostep method. J. Histochem. Cytochem. 23, 200.

Burkot, T.R., Wirtz, R.A. and Lyon, J. (1985) Use of fluorodi-nitrobenzene to identify monoclonal antibodies which are suitable for conjugation to periodate-oxidized horseradish peroxidase. J. Immunol. Methods 84, 25.

Carlsson, J., Drevin, H. and Axen, R. (1978) Protein thiolation and reversible protein-protein conjugation. Biochem. J. $173,723$.

Engvall, E. and Perlmann, P. (1971) Enzyme-linked immunosorbent assay (ELISA). Quantitative assay of immunoglobulin G Immunochemistry 8,871

Ey, P.L., Prowse, S.J. and Jenkin, C.R. (1978) Isolation of pure $\operatorname{IgG}_{1}, \mathrm{IgG}_{2 \mathrm{a}}, \mathrm{IgG}_{2 \mathrm{~b}}$ immunoglobulins from mouse serum using protein ASepharose. Immunochemistry 15, 429.

Ghose, T.I., Blair, A.H. and Kulkarni, P.N. (1983) Preparation of enzyme-linked cytotoxic agents. Methods Enzymol. $93,280$.

Keren, Z., Berke, G. and Gershoni, J.M. (1986) Identification of cell surface glycoproteins by periodate-alkaline phosphatase hydrazide. Anal. Biochem. 155, 182.

Lanner M., Bergquist, R., Carlsson, J. and Huldt, G. (1978) Purification of enzyme-labeled conjugates by affinity chromatography. In: O. Hoffmann-Ostenhof (Ed.), Affinity chromatography. Pergamon Press, Oxford, p. 237.

Nilsson, P., Bergquist, N.R. and Grundy, M.S. (1981) A technique for preparing defined conjugates of horseradish peroxidase and immunoglobulin. J. Immunol. Methods 41, 81.

O'Shannessy, D.J. and Quarles, R.H. (1985) Specific conjugation reactions of the oligosaccharide moieties of immunoglobulins. J. Appl. Biochem. 7, 347.

O'Sullivan, M.J. and Marks, V. (1981) Methods for the preparation of enzyme-antibody conjugates for use in enzyme immunoassay. Methods Enzymol. 73, 147

Shulman, M., Wilde, CD. and Köhler, G. (1978) A better cell line for making hybridomas secreting specific antibodies. Nature, $276,269$.

Voller, A., Bidwell, J. and Bartlett, A. (1976) Microplate enzyme immunoassays for the immunodiagnosis of virus infections. In: N.R. Rose and H. Friedman (Eds), Manual of Clinical Immunology, American society for Microbiology, Washington, DC, p. 506.

Williams, D.G. (1984) Comparison of three conjugation procedures for the formation of tracers for use in enzyme immunoassays. J. Immunol. Methods 72, 261. 